\title{
Natural versus anthropogenic subsidence of Venice
}

SUBJECT AREAS: GEOMORPHOLOGY

GEODYNAMICS

GEOLOGY

HYDROGEOLOGY

Received

16 April 2013

Accepted

29 August 2013

Published

26 September 2013

Correspondence and requests for materials should be addressed to L.T. (luigi.tosi@ismar. cnr.it)

\author{
Luigi Tosi ${ }^{1}$, Pietro Teatini ${ }^{1,2} \&$ Tazio Strozzi ${ }^{3}$
}

${ }^{1}$ Institute of Marine Sciences, National Research Council, Arsenale - Tesa 104, Castello 2737/F, 30122 Venezia, Italy, ${ }^{2}$ Dept. of Civil, Architectural and Environmental Engineering, University of Padova, Via Trieste 63, 35121 Padova, Italy, ${ }^{3}$ GAMMA Remote Sensing AG, Worbstrasse 225, CH-3073 Gümligen, Switzerland.

We detected land displacements of Venice by Persistent Scatterer Interferometry using ERS and ENVISAT C-band and TerraSAR-X and COSMO-SkyMed X-band acquisitions over the periods 1992-2010 and 20082011, respectively. By reason of the larger observation period, the C-band sensors was used to quantify the long-term movements, i.e. the subsidence component primarily ascribed to natural processes. The high resolution X-band satellites reveal a high effectiveness to monitor short-time movements as those induced by human activities. Interpolation of the two datasets and removal of the C-band from the X-band map allows discriminating between the natural and anthropogenic components of the subsidence. A certain variability characterizes the natural subsidence $(0.9 \pm 0.7 \mathrm{~mm} / \mathrm{yr})$, mainly because of the heterogeneous nature and age of the lagoon subsoil. The 2008 displacements show that man interventions are responsible for movements ranging from -10 to $2 \mathrm{~mm} / \mathrm{yr}$. These displacements are generally local and distributed along the margins of the city islands.

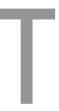
he subsidence of Venice, one of the most beautiful and famous cities in the world, is well known not by reason of the magnitude of the ground movement but because it has seriously compromised the heritage and the safety of the city in relation of its small elevation above the sea.

Depending on the time span considered, different rates of the geological subsidence of the Venice area, generally ranging from 0.6 to $1.6 \mathrm{~mm} / \mathrm{yr}$, have been assessed by various authors ${ }^{1-8}$ using sediment core data and archaeological remains. During historical time, the loss in elevation of Venice was particularly severe in the last century, $\sim 25 \mathrm{~cm}$, i.e. $15 \mathrm{~cm}$ of subsidence mainly due to groundwater pumping in the nearby industrial area and $10 \mathrm{~cm}$ of eustacy. Subsidence and eustacy has both contributed to the loss of land elevation with respect to the mean sea level (or relative sea level rise, RSLR). Its quantification in Venice was obtained through various methodologies and not uniquely quantified ${ }^{9-13}$.

Considering the IPCC (International Panel on Climate Changes) mid-range A1B scenario and the recent land subsidence, the RSLR is expected to range between 17 and $53 \mathrm{~cm}$ by $2100^{12}$. This means that the ground elevation of the historical center, which emerges only $90 \mathrm{~cm}$ above the mean sea, will be drastically reduced and consequently the frequency of "acqua alta" events, i.e. tides higher than $110 \mathrm{~cm}$, will increase from the nowadays 4 times per year to a range between 20 and $250^{12}$. In order to protect the city and its lagoon environment from increased flooding, the multi-billion euro MOSE project is under construction since early 2000s. It consists of rows of mobile gates that will close the inlets connecting the lagoon to the Adriatic Sea when tide events higher than $110 \mathrm{~cm}$ are predicted. Large new structures have been already built and inlet jetties reshaped. Some works are located only $4 \mathrm{~km}$ far from the eastern tip of Venice.

During the last two decades, satellites instrumented with SAR (Synthetic Aperture Radar) sensors provided excellent data for detecting land displacements by interferometric processing. The use of this methodology opens new possibilities for a more accurate interpretation of the land subsidence. The first SAR analysis on Venice was carried out by DInSAR (Differential Interferometric SAR) and provided thousands of measurements much more than the few hundred benchmarks previously used by leveling ${ }^{14}$. More recently the application of Persistent Scatterer Interferometry (PSI) $)^{15,16}$ on C-band satellites has remarkably increased the number of measurable targets, achieving accuracies comparable to that of leveling and permanent GPS. PSI has progressively reduced the use of in-situ traditional techniques to the calibration of the SAR-based methodologies ${ }^{17-19}$. An accurate quantification of the relative and differential movements of single churches, palaces, bridges has become possible with the launch of the new generation X-band sensors characterized by a higher spatial resolution and a shorter revisiting time than C-band. For instance at Venice, the settlement of the MOSE coastal infrastructures, locally up to $-70 \mathrm{~mm} / \mathrm{yr}$, does not affect the historical center ${ }^{20-22}$. 
Although the effect of groundwater pumping ended a few decades ago, a reliable and detail knowledge of the land subsidence affecting the historical center is even more important today due to the city vulnerability continuously increased over the years.

This work is aimed at distinguishing between natural land subsidence and movements induced by anthropogenic activities at Venice using the long- and short-term displacements of the historical center obtained by PSI on C- and X-band images, respectively. PSI provides the cumulative land displacements (natural plus anthropogenic) of the investigated area independently of the radar band. The natural subsidence rate depends on the reference period and, due to the present elevation of Venice with respect to the sea level, it is much more interesting to evaluate the natural displacement over the last few decades, i.e. the present natural land subsidence, than that averaged over geological periods. Concerning anthropogenic land subsidence the contribution due to activities characterized by large scale and long term effects, e.g., that caused by groundwater withdrawals, ended a few decades ago ${ }^{12,18}$. Today, the anthropogenic component of the land subsidence is only due to local, short-time interventions such as restoration works and inherent deformations of historical structures.

Based on these considerations the PSI outcomes are processed to distinguish between the two components of the present land subsidence of Venice. The longest time analysis (C-band dataset) are reasonably used for quantifying the natural component and the shortest analysis (X-band dataset) for highlighting the anthropogenic displacements. The higher pixel resolution of the X-band data enhances the detection of small-scale movements.

\section{Results}

Twenty years of C-band SAR acquisitions, i.e. 1992-2002 for ERS and 2003-2010 for ENVISAT, provided a detailed image of land subsidence at the Venice coastland. The results highlight an almost stable $( \pm 1 \mathrm{~mm} / \mathrm{yr})$ area encompassing the cities of Treviso, Venice and Chioggia and a zone with significant sinking rates $(3-6 \mathrm{~mm} / \mathrm{yr})$ in the northern coastland. A large variability (from -4 to $1 \mathrm{~mm} / \mathrm{yr}$ ) characterizes the southern coastland (Fig. 1).

Focusing on the historical center of Venice, the displacement pictures of the city over the two consecutive periods covered by C-band images are comparable and characterized by a small variability (Fig. 2a and b). The mean subsidence rate and the standard deviation amount to $0.8 \pm 0.7$ and $1.0 \pm 0.7 \mathrm{~mm} / \mathrm{yr}$ with ERS and ENVISAT, respectively. Note that the standard deviations are representative of the ground motion variability at the whole city scale and not related to the uncertainty of the velocity of the radar reflectors (i.e. measurement accuracy). On the average the Cband measurements show that about $80-85 \%$ of the city displacements range between 0 and $-1.5 \mathrm{~mm} / \mathrm{yr}$ and $15 \%$ from -1.5 to $-3 \mathrm{~mm} / \mathrm{yr}$. Taking into account that PSI requires a coherent target response in the whole image dataset, i.e. a radar reflector must rest on the soil over the entire monitoring period and cannot experienced abrupt movements to be measurable ${ }^{23,24}$, this long-term map can be

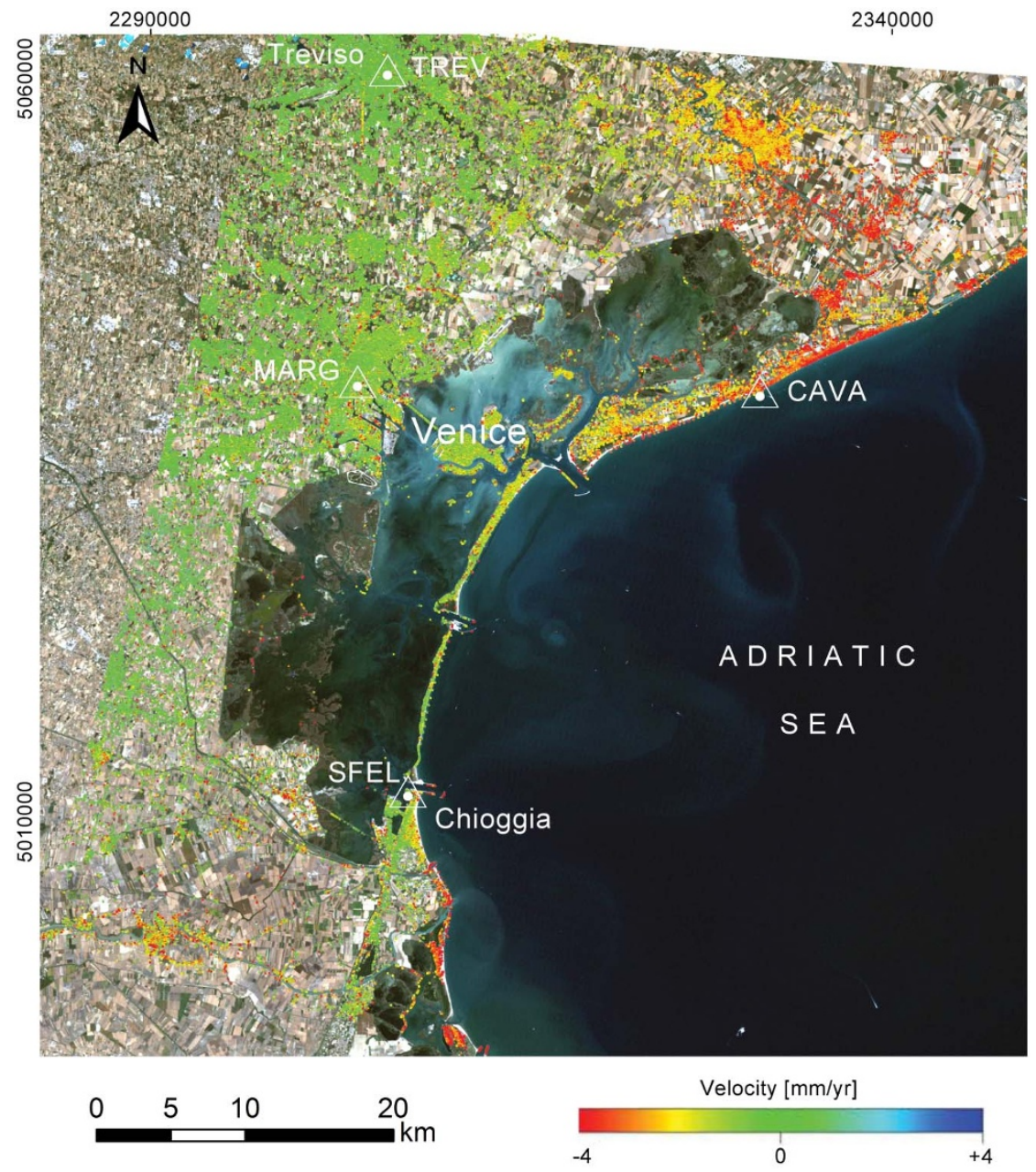

Figure 1 Velocity map (mm/yr) for the Venice coastland obtained by IPTA on ENVISAT images acquired between 2003 and 2010 . Positive values mean uplift, negative land subsidence. White triangles show the position of the permanent GPS stations (CGPS). Base map used is a Landsat image obtained from the US Geological Survey - Earth Resources Observation and Science (EROS) Center and composed in ESRI ArcMAP 9.3. 

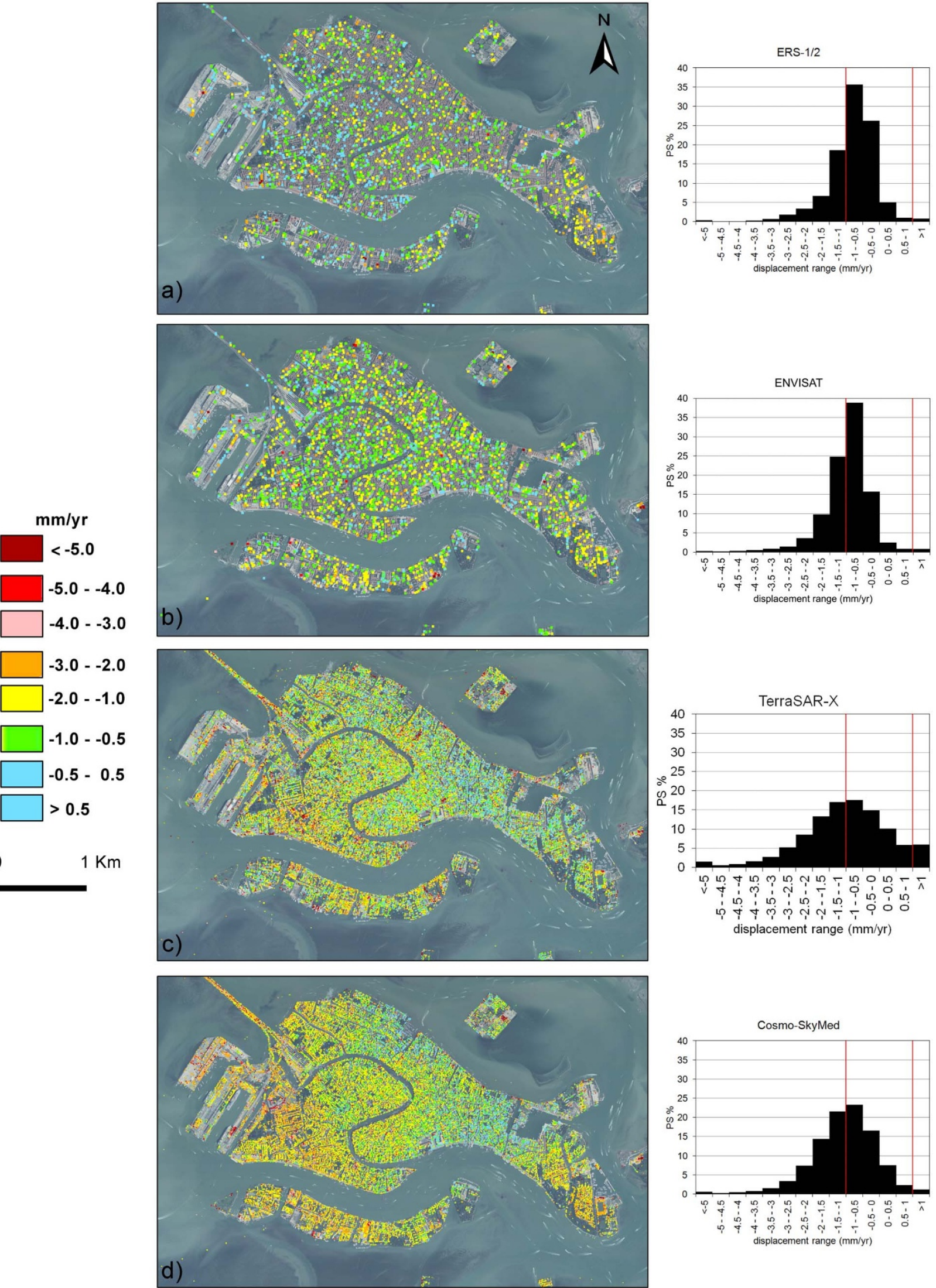

Figure $2 \mid$ Average displacement rates (mm/yr) obtained by IPTA at Venice: (a) ERS from 1992 to 2002; (b) ENVISAT from 2003 to 2010; (c) TerraSAR-X from March 2008 and January 2009; (d) COSMO-SkyMed from 2008 to 2011. The image background is an aerophotograph acquired in 2009. Negative values indicate settlement, positive mean uplift. The frequency distribution of the displacements for each map is provided to the right. The red lines separate the subsiding ( $<-1 \mathrm{~mm} / \mathrm{yr}$ ), stable (between -1 and $1 \mathrm{~mm} / \mathrm{yr}$ ), and uplifiting $(>1 \mathrm{~mm} / \mathrm{yr})$ portions. Figure composed in ESRI ArcMAP 9.3. 
interpreted as a reliable picture of the natural subsidence that is presently affecting Venice.

The very high spatial resolution of the X-band satellites and their short revisiting time makes it possible to investigate urban settlements with a level of detail never obtained in the past. Although the number of available TerraSAR-X and COSMO-SkyMed scenes is equivalent, they cover 11 months (from March 2008 to January 2009 for TerraSAR-X) and 35 months (form September 2008 to July 2011 for Cosmo-SkyMed), with different sampling rates. The PSI outcomes (Fig. 2c and d) show a density of the detected scatters one order of magnitude larger than that obtained by the C-band sensors. The statistical analysis of the displacement distributions points out that the average rates are almost equal with the two satellites, i.e. $-1.0 \mathrm{~mm} / \mathrm{yr}$ with TerraSAR-X and -1.1 with COSMO-SkyMed, and also quite similar to those detected by $\mathrm{C}$-band satellites. The standard deviation is characterized by significant larger values equal to 1.6 and $1.0 \mathrm{~mm} / \mathrm{yr}$ with TerraSAR-X and COSMO-SkyMed, respectively. The frequency distribution of the measured displacements shows that $50 \%$ and $60 \%$ of the radar reflectors are characterized by a movement between 0 and $-1.5 \mathrm{~mm} / \mathrm{yr}$ for TerraSAR-X and COSMO-SkyMed, respectively, and 25\% range from -1.5 and $-3.0 \mathrm{~mm} / \mathrm{yr}$ for both the X-band sensors.

The higher variability of the displacements obtained by the $\mathrm{X}$ band scenes, in particular TerraSAR-X, is an added value of the short-term analysis combined with the satellite characteristics, i.e. a small revisiting time and the 2-m pixel spacing. As $\mathrm{C}$ - and $\mathrm{X}$-band analyses show similar rates of the average displacement, i.e. the natural component of the subsidence, it is reasonable to assume that the difference between the movements provided by ERS/ENVISAT and TerraSAR-X/COSMO-SkyMed is likely representative of the effects caused by anthropogenic activities.

This hypothesis is supported by a proper processing of the two Cand $\mathrm{X}$-band measurements. The two datasets are interpolated by the Kriging method on the same regular grid covering the whole city. The grid spacing, fixed at $50 \mathrm{~m}$, has been appropriately tuned to simultaneously:
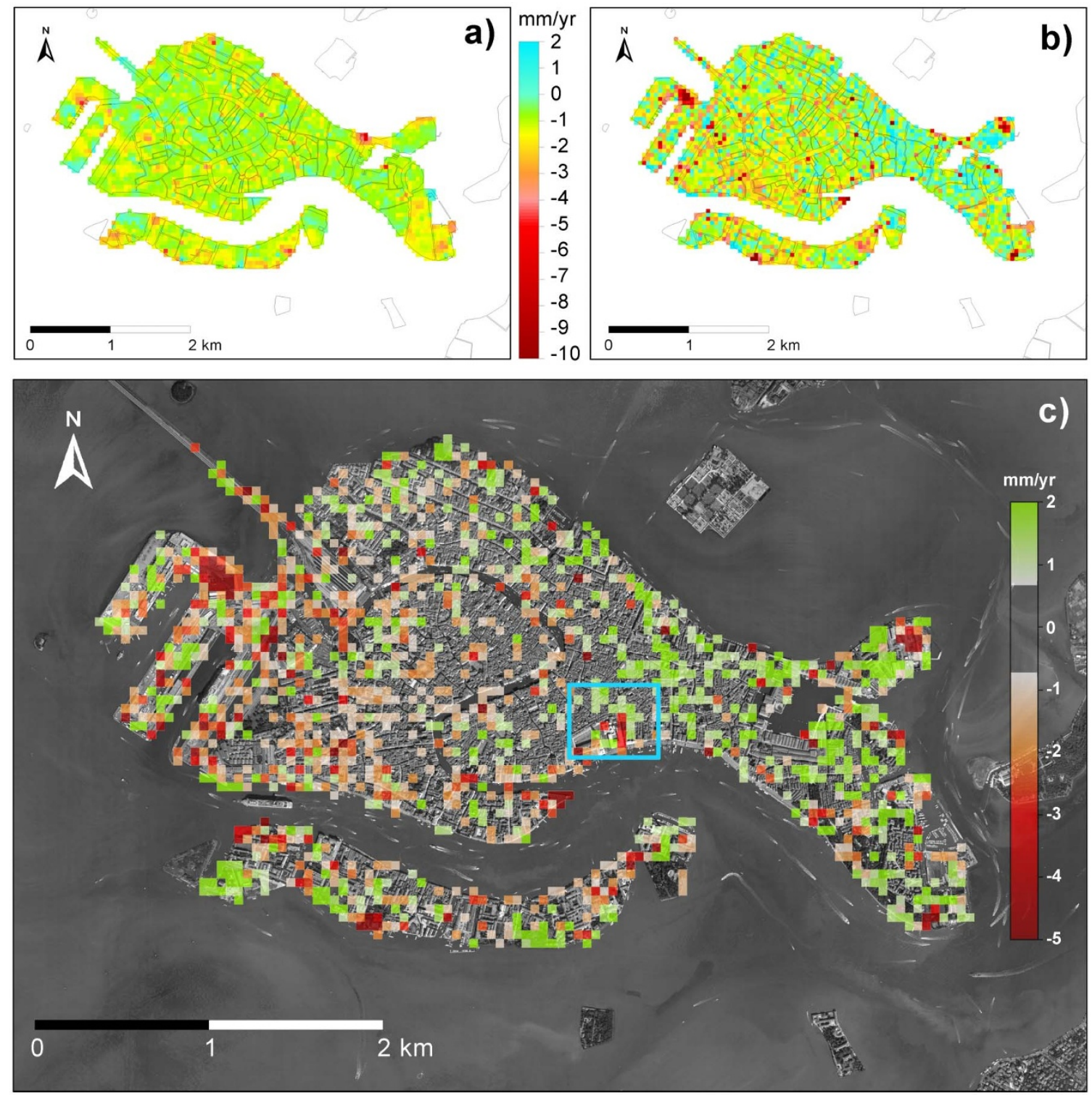

Figure 3 Maps of the displacement rate (positive velocities indicate site uplift, negative velocities indicate land subsidence) obtained by interpolating: (a) the ERS-ENVISAT and (b) the TerraSAR-X IPTA results on a regular $50 \mathrm{~m}$ grid. (c) Difference between the TerraSAR-X and ERS-ENVISAT maps representing an estimate of the present anthropogenic land movements at Venice. Negative and positive rates indicate areas where human activities are responsible for land settlements or reduce the natural subsidence, respectively. The light-blue box in (c) refers to the area investigated in Fig. 5. Maps composed in Golden Software Surfer 10. 
- filter out the outlier values provided by the C-band analysis; these outliers are referred to a few $(\sim 5 \%)$ unstable targets, generally due to human effects, scattered within the majority of the solution representing the natural processes;

- keep the heterogeneity of the displacements detected by the Xband investigation.

Finally the quantification of man-induced displacements is obtained by removing the C-band interpolated map from the X-band interpolated solution. This procedure has been applied to the 19922010 mean velocities provided by ERS/ENVISAT (Fig. 3a) and to 2008 TerraSAR-X results (Fig. 3b). This latter has been preferred to COSMO-SkyMed because of $i$ ) the higher ratio between the number of available images and the acquisition period, ii) the shorter acquisition period and its fall within the monitoring interval covered by the C-band images, and iii) the better quality of the PSI outcome due to the variability (from 16 to 144 days) of two consecutive COSMOSkyMed acquisitions. Notice that the $\sim 1$-year long dataset from TerraSAR-X is sufficient to filter out possible cyclical fluctuations, if any, due to season climate effects (e.g., precipitation, aquifer recharge, temperature, tidal regime).

The comparison between the two maps obtained by interpolating the PSI results points out the uniformity (in the range between 0 and $-1 \mathrm{~mm} / \mathrm{yr}$ ) of the long-term displacement rates (Fig. 3a) and the large variability of the short-term movements (Fig. 3b) that are superposed to a background velocity similar to that given by ERS/ ENVISAT (Fig. 3a). The map of the differences (Fig. 3c) shows that most of the city is subsiding only due to natural components. However, about $25 \%$ of city has experienced in 2008 some movements due to anthropogenic causes. Generally, the man-induced activities contribute to a subsidence larger than the natural (15\%) but there are some areas (10\%) where the short-term sinking is smaller than the long-term subsidence.

\section{Discussion}

Venice is no more subsiding due to groundwater pumping. However, the peculiarly of the city position, located above about $1000 \mathrm{~m}$ thick

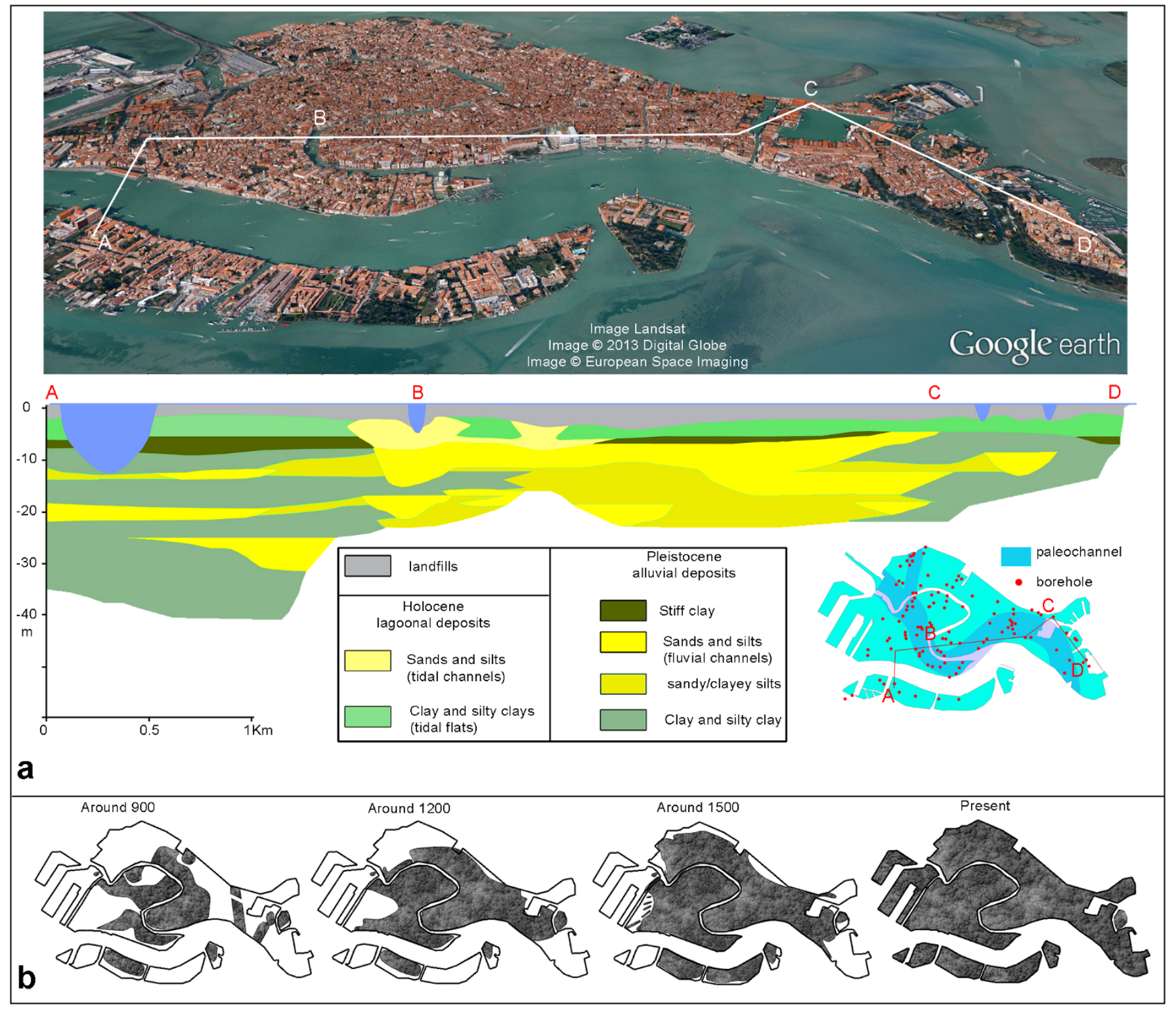

Figure 4 | (a) Architecture of the shallow subsoil of Venice along the alignment A-D. The location of the geological data is shown in the inset ${ }^{27}$. The satellite image is from Google Earth, data source: Landsat, 2013 Digital Globe, and European Space Imaging. (b) Growth in area of Venice from 900 A.D. to present. 
Quaternary deposits, and the structure of the historical center, which is funded by wooden piles established on sand-clay layers and artificial reclamations of tidal flats and channels, require to continue the monitoring of the city displacements. The use of C- and X-band sensors has allowed quantifying the natural and man-induced components of the present land subsidence.

The "present natural" subsidence rate of the "historical center of Venice" averages $0.8-1.0 \mathrm{~mm} / \mathrm{yr}$ consistently with the "geological" subsidence of the "Venice area" of $\sim 1.3 \mathrm{~mm} / \mathrm{yr}^{2,5}$ and $\sim 0.6 \mathrm{~mm} / \mathrm{yr}^{25}$.

However, because geological subsidence was estimated at least at Kyr scale, it is not representative of the present natural subsidence of the entire city. Local zones and restricted portions are subsiding at faster rates, i.e. $1-3 \mathrm{~mm} / \mathrm{yr}$, due the heterogeneous nature of the shallow subsoil, i.e. natural or landfill (Fig. 4a), growth of the city (Fig. 4b), and different depth of foundation and load of the historical palaces. An even more large variability of the present natural subsidence has been recently detected in the nearby Po River delta ${ }^{26}$.

In particular, the occurrence of buried sandy levees of channel systems (perhaps the primeval Canal Grande ${ }^{27}$ ) well corresponds with the sectors of the city characterized by smaller settlements. Conversely, zones established on more compressible silty and clayey alluvial and tidal plain deposits sink at higher rates (Fig. 4a). Also the age of the landfills, i.e. the growth of the primeval island of Venice and the buildup of historical center, is correlated with the subsidence variability ${ }^{14}$. The city developed over ancient well-consolidated sandy islands during the first millennium, and the following expansions were done by reclaiming and filling parts of the lagoon tidal flats and channels (Fig. 4b). The older part of the city, which generally corresponds with the city extension before 1500 , shows lower sinking rates or quite stable sectors.

The present anthropogenic displacements occur at very local scale and are heterogeneously distributed with values ranging from -10 and $2 \mathrm{~mm} / \mathrm{yr}$ in 2008. They are caused by conservation and reconstruction processes to preserve the building heritage (Fig. 5) together with urban maintenance activities such as restoring the embankment walls to guarantee the stability of the canal edges. Moreover, because the sinking zones are generally concentrated along the main channels bounding and crossing the city (Fig. 3c), waves induced by the intensive boat and ship traffic likely contribute by waking and eroding the fragile masonry canal banks and the building foundations ${ }^{28}$. Geotechnical applications such as micropiles, anchors, jet grouting aimed at improving the subsoil characteristics are likely responsible for the greater stability locally observed in some portions of the city as of 2008 (Fig. 3c).

The following conclusions are worth summarizing: a) the combined use of long-term C-band and short-term X-band SAR
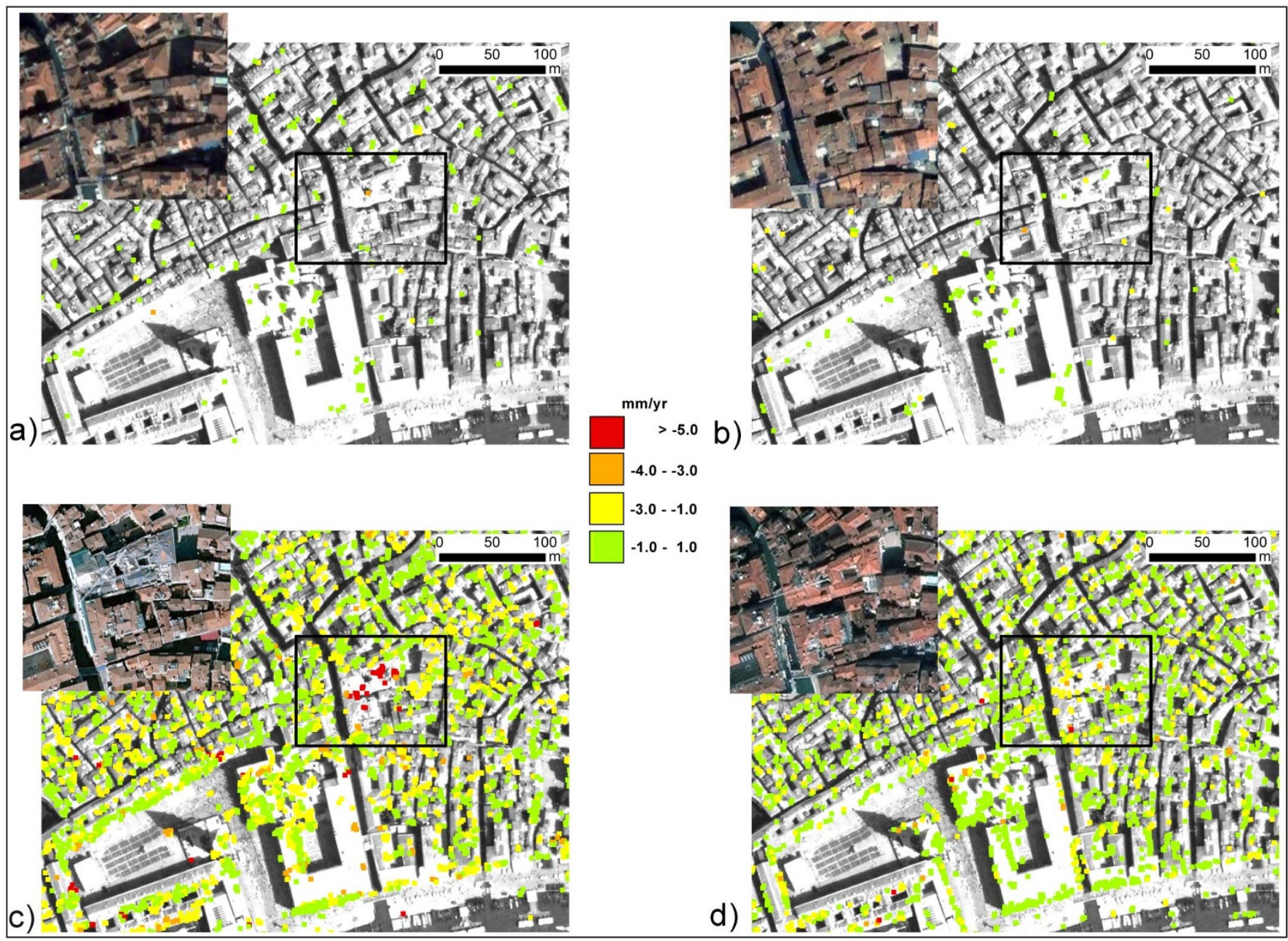

Figure 5 Example of temporary high sinking rates due to restoration works of single palaces. Average displacement rates (mm/yr) obtained by IPTA at a portion of the city NE of St. Mark's Basilica: (a) ERS, (b) ENVISAT, (c) TerraSAR-X, and (d) COSMO-SkyMed. The picture comparison highlights how the short-term analysis performed with the TerraSAR-X images (c) captures the effect of the works carried out in 2007 (see the corresponding aerial photograph shown in the inset). The longer time series acquired by C-band sensors ( $\mathrm{a}$ and $\mathrm{b}$ ) show that before 2007 the area was affected by the natural subsidence only $(\sim 1 \mathrm{~mm} / \mathrm{yr})$. After the end of the works, the average rates reduce following the consolidation process, as detected by COSMO-SkyMed. Figure composed in ESRI ArcMAP 9.3. 
Table 1 | Characteristics of the satellites sensors and SAR images. ERS-1/2 and ENVISAT SAR data processed to same Doppler

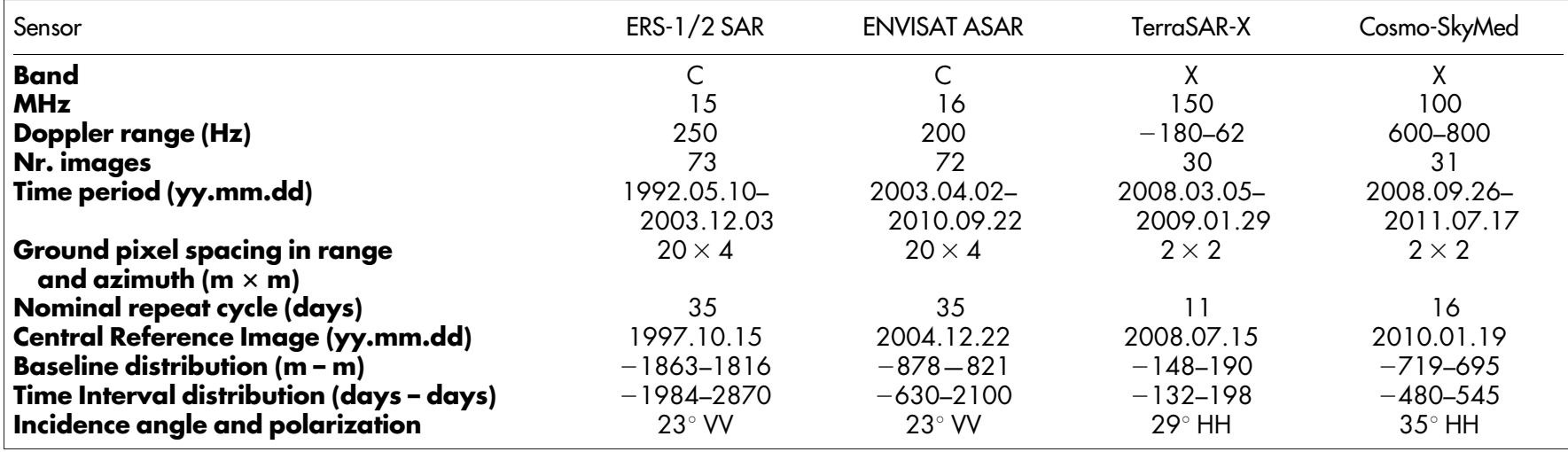

investigations offers a unique opportunity to discriminate between natural and anthropogenic land subsidence; b) the present average natural subsidence of Venice has been quantified in $0.8-1.0 \mathrm{~mm} / \mathrm{yr}$, a value which is in agreement with the average rate calculated for the geological subsidence at Kyr scale. Moreover, a certain variability has been detected and correlated with the characteristics of the shallow subsoil and the growth of the historical center; c) Venice is still experiencing land subsidence due to human activities, mainly restoration works. However this component affects the city at very local scale for short time intervals with rates up to $10 \mathrm{~mm} / \mathrm{yr}$.

\section{Methods}

The Interferometric Point Target Analysis (IPTA) ${ }^{16,29}$, a Persistent Scatterer Interferometry (PSI $)^{15}$ implementation chain, is applied on stripmap images acquired by C-band (ERS, ENVISAT) and X-band (TerraSAR-X, COSMO-SkyMed) satellites.
IPTA combines data from SAR images acquired from repeat track orbits to exploit the phase differences of the radar signals that are related only to surface displacement occurring between the image acquisitions. IPTA systematically removes the contribution of surface topography to the interferometric phase and mitigates the variability in the tropospheric path delay by utilizing differences in the spatial and temporal characteristics of the phase due to deformation and atmosphere. IPTA-derived deformation measurements are interpreted for a number of point radar-bright and radar-phase-stable targets (PTs) that are coherent over the entire time interval and cover the monitored area as a sparse "natural" benchmark net ${ }^{29}$.

C-band and X-band sensors have different features and are characterized by different revisiting time (Tab. 1). The images covering the study area were acquired regularly by the two C-band satellites and TerraSAR-X. A very variable time interval between two consecutive images characterizes the COSMO-SkyMed acquisitions, up to 144 days from February 23, 2011, and 3 July 17, 2011.

The selection of candidate point targets is based on a temporal mean-to-standard deviation ratio of the co-registered SAR intensity images ${ }^{29,20}$ above 1.4 for ERS, 1.25 for ENVISAT, 1.6 for TerraSAR-X, and 1.4 for COSMO-SkyMed and a spectral correlation averaged over the single look complex stack of more than 0.5 for both ERS

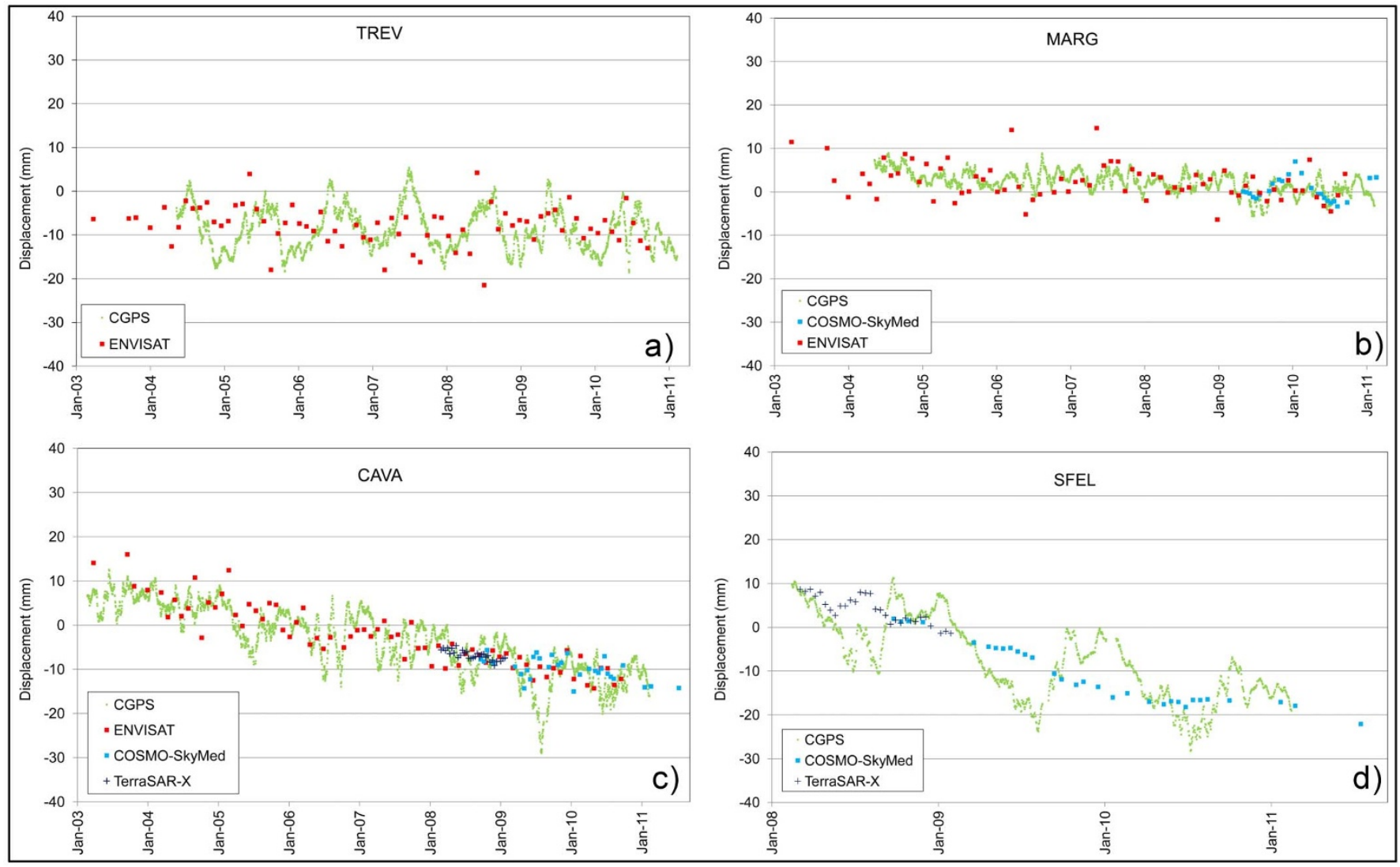

Figure 6 Data validation. Comparison between the displacement histories recorded by the (a) TREV, (b) MARG, (c) CAVA, (d) SFEL CGPS and those obtained by IPTA on the persistent reflectors in the nearby of the permanent stations. 
Remote Sensing Symposium (IGARSS 2003), IEEE International 7, 4362-4364 (2003).

17. Teatini, P. et al. Short- and long-time displacements in the Venice coastland by synthetic aperture radar interferometric point target analysis. J. Geophys. Res. 112, F01012 (2007).

18. Tosi, L. et al. Ground surface dynamics in the northern Adriatic coastland over the last two decades. Rend. Fis. Acc. Lincei 21, S115-S129 (2010).

19. Teatini, P. et al. Resolving land subsidence within the Venice Lagoon by persistent scatterer SAR interferometry. Phys. Chem. Earth. Pt. A/B/C 40, 72-79 (2012).

20. Strozzi, T., Teatini, P. \& Tosi, L. TerraSAR-X reveals the impact of the mobile barrier works on Venice coastland stability. Remote Sens. Environ. 113, 2682-2688 (2009).

21. Tosi, L., Strozzi, T. \& Teatini, P. COSMO-SkyMed versus TerraSAR-X-based interferometry for monitoring the mose settlements at the Venice lagoon inlets Proceedings of the Geoscience and Remote Sensing Symposium (IGARSS 2012), IEEE International 2837-2840 (2012).

22. Tosi, L., Teatini, P., Bincoletto, L., Simonini, P. \& Strozzi, T. Integrating geotechnical and interferometric SAR measurements for secondary compressibility characterization of coastal soils. Surv. Geophys. 33, 907-926 (2012).

23. Crosetto, M. et al. Validation of Persistent Scatterers Interferometry over a mining test site: results of the PSIC4 project. Proceedings of the Envisat Symposium 2007 ESA SP-636 (2007).

24. Crosetto, M. et al. Ground motion monitoring using SAR interferometry: quality assessment. European Geologist 26, 12-15 (2009).

25. Antonioli, F. et al. Relative sea-level rise and asymmetric subsidence in the northern Adriatic. Rendiconti online Soc. Geol. It. 9, 5-8 (2009).

26. Teatini, P., Tosi, L. \& Strozzi, T. Quantitative evidence that compaction of Holocene sediments drives the present land subsidence of the Po Delta, Italy. J. Geophys. Res. 116, B08407 (2011).

27. Zezza, F. The sedimentary structure of Upper Pleistocene-Holocene deposits in Venice and its effects on the stability of the historic centre. Rend. Fis. Acc. Lincei 21, S211-S227 (2010)

28. Doglioni, F., Roberti, G. M., Trovò, F., Bondanelli, M. \& Squassina, A. A structural damage atlas for Venice. Scientific Research and Safeguarding of Venice 6, 133-146 (2007).

29. Wegmüller, U., Werner, C., Strozzi, T. \& Wiesmann, A. Multitemporal interferometric point target analysis. Ser. Remote Sens. 3, 136-144 (2004).

30. Werner, C., Wegmüller, U., Strozzi, T. \& Wiesmann, A. Processing strategies for phase unwrapping for INSAR applications. Proceedings of the European Conference on Synthetic Aperture Radar (EUSAR 2002) 1, 353-356 (2002).

31. Teatini, P. et al. Mapping regional land displacements in the Venice coastland by an integrated monitoring system. Remote Sens. Environ. 98, 403-413 (2005).

32. Bock, Y., Wdowinski, S., Ferretti, A., Novali, F. \& Fumagalli, A. Recent subsidence of the Venice Lagoon from continuous GPS and interferometric synthetic aperture radar. Geochem. Geophys. Geosyst. 13, Q03023 (2012).

33. Teatini, P., Tosi, L. \& Strozzi, T. Comment on "Recent subsidence of the Venice Lagoon from continuous GPS and interferometric synthetic aperture radar" by Y. Bock, S. Wdowinski, A. Ferretti, F. Novali, and A. Fumagalli. Geochem. Geophys. Geosyst. 13, Q07008 (2012).

34. Tosi, L., Teatini, P. Carbognin, L. \& Frankenfield, J. A new project to monitor land subsidence in the northern Venice coastland (Italy). Environ. Geol. 52, 889-898 (2007).

35. Altamimi, Z., Sillard, P. \& Boucher, C. ITRF2000: A new release of the International Terrestrial Reference Frame for Earth science applications. J. Geophys. Res. 107, 2214 (2002).

36. Altamimi, Z., Collilieux, X., Legrand, J., Garayt, B. \& Boucher, C. ITRF2005: A new release of the International Terrestrial Reference Frame based on time series of station positions and Earth Orientation Parameters. J. Geophys. Res. 112, B09401 (2007).

\section{Acknowledgements}

This work has been developed in the framework of the Action 2 (SP3-WP1) "Hydrogeology, subsidence and relative sea level changes" funded by the Flagship Project RITMARE - The Italian Research for the Sea - coordinated by the Italian National Research Council and funded by the Italian Ministry of Education, University and Research within the National Research Program 2011-2013. Data courtesy: (1) COSMO-SkyMed AO, Project ID 2100 ๑ ASI "Land movements in the Venice Lagoon: measuring the natural/regional and anthropogenic/local components by SAR Interferometric Point Target Analysis (IPTA); (2) TerraSAR-X, Project COA0612 ${ }^{\odot}$ DLR “Assessing vertical movements of natural tidal landforms and anthropogenic structures at the Venice Lagoon inlets" and (3) GPS and ENVISAT, INLET Project, funded by Magistrato alle Acque (Venice Water Authority) through its concessionary Consorzio Venezia Nuova. The authors thank Prof. Fulvio Zezza (IUAV University, Venice) for making available geological data and fruitful discussions.

\section{Author contributions}

T.S. performed IPTA analysis by GAMMA Software. L.T. and P.T. validated PS data by CGPS, processed and analyzed the outcomes, interpreted data and wrote the paper. All authors discussed and commented on the methods, results and the manuscript. 


\section{Additional information}

Competing financial interests: The authors declare no competing financial interests.

How to cite this article: Tosi, L., Teatini, P. \& Strozzi, T. Natural versus anthropogenic subsidence of Venice. Sci. Rep. 3, 2710; DOI:10.1038/srep02710 (2013). cc) (i) $\Theta$ This work is licensed under a Creative Commons AttributionBY NC ND NonCommercial-NoDerivs 3.0 Unported license. To view a copy of this license, visit http://creativecommons.org/licenses/by-nc-nd/3.0 